\title{
UM PANORAMA SOBRE A ABORDAGEM AMBIENTAL NO CURRÍCULO DE CURSOS DE FORMAÇÃO INICIAL DE PROFESSORES DE QUÍMICA DA REGIÃO SUDESTE
}

\author{
Jocélia Barbosa Pereira, Maria Lúcia A. de M. Campos, Simara Maria Tavares Nunes e Daniela Gonçalves de Abreu* \\ Departamento de Química, Centro de Ensino Integrado de Química, Faculdade de Filosofia, Ciências e Letras de Ribeirão Preto, \\ Universidade de São Paulo, 14040-901 Ribeirão Preto-SP, Brasil
}

Recebido em 8/11/07; aceito em 18/8/08; publicado na web em 5/2/09

\begin{abstract}
AN OVERVIEW OF HOW THE CURRICULA TAKEN BY FUTURE CHEMISTRY TEACHERS IN SOUTHEASTERN BRAZIL'S PUBLIC UNIVERSITIES APPROACH ENVIRONMENTAL ISSUES. This work analysed the contents of 701 disciplines from 22 chemistry courses that prepare chemistry teachers in 16 public Universities in Southeastern Brazil. Only a small number (23) of disciplines showed an explicit relationship between human activities and the environment. A total of 11 theoretical and 193 experimental disciplines explored to some extent scientific and technological aspects related to the environment, but did not include their relationship with society. As the experimental disciplines supposedly include some kind of waste treatment, this may explain why secondary school chemistry teachers work mainly on recycling programs and waste issues at their schools. The aim of this work is to provide information on which to base a much needed discussion about how to better prepare our chemistry teachers to act as Environmental Educators at school, as the Brazilian Education Legislation requires.
\end{abstract}

Keywords: environmental education; curricula; chemistry teachers.

\section{INTRODUÇÃo}

Com o objetivo de elaborar a 'cartografia' da pesquisa em Educação Ambiental (EA) no Brasil, Reigota ${ }^{1}$ fez um minucioso levantamento das publicações brasileiras de 1984 a 2002. O autor concluiu que a temática ambiental na produção nacional é muito variada, dominando a análise da relação entre natureza e cultura em temas como "degradação ambiental, crise ambiental, problemas sócioambientais, alterações ambientais globais", entre outras. A maior produção ocorreu em programas de Pós-graduação em Educação (56\%), havendo também produções em programas de Saúde Pública, Ecologia, Educação Ambiental e áreas multidisciplinares. Foram 287 teses e dissertações analisadas, sendo que a área de Química como tema ou como programa de pós-graduação não foi mencionada nesta cartografia. Ainda que este levantamento tenha abrangido até o ano de 2002, é notória a pouca produção de trabalhos de EA voltados para a área de Química.

Em estudo realizado com professores de várias escolas de ensino médio da cidade de Ribeirão Preto (SP) e região, foi observado que os professores de Química, quando comparados com os professores de Biologia, apresentaram maiores dificuldades em propor ações que ultrapassem o nível informativo e de sensibilização da EA². Evidenciase, desta forma, a necessidade de se conhecer quais são os elementos vinculados à temática ambiental que, ainda que estejam presentes na formação dos professores de Química, não têm garantido o preparo adequado para abordar a EA na escola básica.

Assim como Silva, ${ }^{3}$ consideramos o currículo como um "documento de identidade", reflexo do momento histórico em questão e diretamente vinculado às relações de poder, à organização e estruturação da sociedade e à visão de mundo do grupo social dominante. Consideramos que tanto o currículo formalmente explícito, como também as práticas pedagógicas não explícitas, mas constituintes do chamado "currículo oculto", são fundamentais para a formação profissional. No entanto, este trabalho teve como foco o currículo prescrito.

*e-mail: danielaga@ ffclrp.usp.br
Procurou-se encontrar indícios sobre a abordagem de conteúdos ligados à temática ambiental na formação inicial de professores de Química, por meio da análise de programas e ementas de disciplinas de química e ensino de química, que explicitamente fazem parte de currículos de Cursos de Licenciatura em Química.

Esta pesquisa, longe de ser conclusiva, tem por objetivo gerar um panorama para subsidiar novas discussões e estudos sobre as possíveis alternativas para a consolidação da temática ambiental na formação de professores de Química.

\section{ASPECTOS LIGADOS À EDUCAÇÃO AMBIENTAL}

Na década de 70, a EA foi concebida como uma preocupação dos movimentos ecológicos com uma prática de conscientização capaz de alertar sobre a finitude e má distribuição no acesso aos recursos naturais, envolvendo as pessoas em ações sociais consideradas ambientalmente adequadas. ${ }^{4}$ Em termos de ensino de ciências, tem-se a origem, nesta época, do chamado movimento Ciência, Tecnologia e Sociedade (CTS). ${ }^{5}$ A partir de então, inicia-se uma discussão em torno da necessidade de formar o cidadão que, entre outras coisas, seja consciente de suas responsabilidades na sociedade. Aos poucos, a EA vai se transformando numa proposta educativa. ${ }^{4} \mathrm{~A}$ grande relevância da Conferência Intergovernamental de Tbilissi na Geórgia, em 1977, foi o seu rompimento paradigmático, pois os eventos científicos anteriores ainda estavam reduzidos ao sistema ecológico, ou seja, supunham uma educação conservacionista.

Na década de 80, o termo "Educação Ambiental" torna-se globalmente popular e, desde então, tem passado por várias reformulações. ${ }^{6}$ Atualmente, a EA tem sido apresentada como uma nova dimensão a ser incorporada ao processo educacional, por trazer à tona a discussão sobre as questões ambientais e as conseqüentes transformações de conhecimento, de valores e atitudes diante de uma nova realidade a ser construída. ${ }^{7}$ A divulgação do $4^{\circ}$ relatório elaborado pelo Painel Intergovernamental sobre Mudanças Climáticas (IPCC) evidencia a necessidade de mudança de valores e paradigmas pela sociedade para se atingir um desenvolvimento sustentável. Assim, a EA pode 
ser ponto chave no desenvolvimento de uma sociedade sustentável e socialmente mais justa.

No Brasil, uma ação significativa que reconheceu a importância da questão ambiental foi a Lei de Diretrizes e Bases da Educação Nacional $^{8}$ (LDB 9394/96), que passou a considerar a compreensão do ambiente natural como fundamental para a Educação Básica. Houve também a inclusão da temática ambiental como um dos temas transversais nos Parâmetros Curriculares Nacionais $(\mathrm{PCN})^{9}$ para a escola básica.

Desde a promulgação da Constituição Brasileira de 1988, em seu artigo 25 - inciso 6, define-se como incumbência do Poder Público a promoção da EA em todos os níveis de ensino, bem como a conscientização pública para a preservação do meio ambiente. Este inciso foi regulamentado pela Lei Federal 9.795 (27/04/99), que instituiu a Política Nacional de Educação Ambiental (PNEA), que por sua vez foi regulamentada pelo Decreto 4.281 (julho/2002). Há no país, portanto, amparo legal que pode ser utilizado como argumento para a implementação de programas formativos em EA, em qualquer nível de ensino. O estudo sobre formação ambiental no nível superior tem recebido destaque nos últimos anos. ${ }^{10,11}$ Sorrentino ${ }^{11}$ discute que as ações mais comuns adotadas por algumas Universidades têm sido a incorporação de disciplinas, geralmente optativas no caso das chamadas carreiras técnicas ou criação de comissões interdepartamentais, que tenham como objetivo a promoção da EA na Universidade.

Em se tratando dos Cursos de Química (Bacharelado e Licenciatura), as Diretrizes Curriculares Nacionais ${ }^{12}$ elaboradas em atendimento à Lei de Diretrizes e Bases da Educação Nacional $(9394 / 96)^{8}$ e ao Edital 04/97 da Secretaria da Educação Superior do MEC, estabelecem que, além da formação didática, científica e tecnológica sólida do profissional, deve também ser garantida uma formação humanística que dê condições ao egresso de exercer a profissão em defesa da vida, do ambiente e do bem estar dos cidadãos. O profissional em Química também deverá ser capaz de avaliar criticamente a aplicação do conhecimento em Química, tendo em vista o diagnóstico e o equacionamento de questões sociais e ambientais. ${ }^{13}$ No entanto, de acordo com o Programa Parâmetros em Ação - Meio Ambiente na Escola, ${ }^{14}$ da Secretaria de Educação Fundamental, "os currículos dos cursos de formação inicial de professores e programas de formação continuada não têm efetivamente garantido o preparo necessário para o exercício adequado das atividades profissionais com relação à promoção da $E A^{\prime \prime}$ (p. 21).

\section{Referenciais teóricos}

Nos currículos estão contidos diferentes discursos e intencionalidades daqueles que os produziram; desta forma, a seleção de conteúdos não é neutra. É possível ler no currículo a estrutura social, o pensamento dominante e as estratégias de poder. ${ }^{15} \mathrm{~A}$ análise de currículos, tanto em seu conteúdo como em suas formas, é fundamental para entender os objetivos das instituições escolares em seus diferentes níveis e modalidades. Sacristán ${ }^{16}$ propõe uma concepção processual de currículo e procura situar a política curricular como elo entre interesses políticos, teorias curriculares e práticas escolares. Ao explorar o processo curricular, o referido autor divide-o em diferentes níveis ou fases - currículo prescrito, currículo apresentado aos professores, currículo moldado pelos professores, currículo em ação e currículo avaliado.

O professor é um agente ativo decisivo na concretização dos conteúdos e significados dos currículos, moldando a partir de sua cultura profissional qualquer proposta que lhe é feita, seja através da prescrição administrativa, seja do currículo elaborado pelos materiais, guias, livros-texto, etc. Pode-se dizer que o professor seja um tradutor que intervém na configuração dos significados das propostas curriculares. ${ }^{16} \mathrm{O}$ plano ou programação que os professores fazem é um momento de especial significado nessa tradução. Sacristán ${ }^{16}$ também nos diz que o currículo é um ambiente de interação no qual se entrecruzam processos, agentes e âmbitos diversos que, num verdadeiro e complexo processo social, lhe dão significado prático e real. E, para torná-lo situado perante as necessidades vigentes, tais interações precisam ser periodicamente analisadas.

Desde 2000, foi constituída a rede ACES (Ambientalización Curricular de los Estúdios Superiores), formada por 11 Universidades, sendo 5 européias e 6 latino-americanas, com objetivo de diagnosticar o grau de ambientalização curricular dos cursos superiores nas Universidades participantes. ${ }^{17}$ No Brasil, participaram da referida rede a Universidade Estadual de Campinas (UNICAMP), Universidade Estadual Paulista (UNESP) - Campus Rio Claro e Universidade Federal de São Carlos (UFSCar). A Ambientalização Curricular envolve três dimensões: a do currículo stricto sensu (disciplinas e grade curricular de cada curso); aquelas relacionadas com os aspectos formativos extra-curriculares (que incluem os aspectos da gestão ambiental institucional definida por sua política ambiental) e as que dizem respeito à dimensão da participação cidadã, que extrapola o âmbito das atividades institucionais, estando no nível das ações individuais ou de grupos dedicados às práticas sustentáveis, no próprio campus ou fora dele. Apesar de considerar a importância desta análise considerando várias dimensões, e também compreender que o currículo implica uma integração entre a dimensão escrita e a vivida, neste trabalho optamos por analisar os programas de disciplinas de Cursos de Licenciatura em Química, que representam o currículo prescrito e apresentado aos professores. É claro que uma análise do currículo moldado e desenvolvido pelos professores nos daria uma idéia mais completa sobre a formação ambiental nos Cursos de Química. No entanto, acreditamos que o currículo prescrito, de certa forma, nos fornece indícios que podem apoiar e incentivar discussões sobre formação inicial de professores de Química.

\section{DESENVOLVIMENTO DA PESQUISA}

Neste trabalho, optou-se por uma abordagem qualitativa ${ }^{18}$ e quantitativa. Desenvolveu-se uma pesquisa diagnóstico-avaliativa, cujo objetivo é a verificação dos processos desenvolvidos com seus resultados, o que possibilita novas orientações das ações. ${ }^{19}$

O método utilizado para a coleta de dados foi análise documental que, segundo Caulley, ${ }^{20}$ busca identificar informações factuais nos documentos a partir de questões ou hipóteses de interesse. Qualquer material escrito como, por exemplo, leis e regulamentos, normas, pareceres, cartas, memorandos, diários pessoais, autobiografias, jornais, revistas, discursos, roteiros de programas, entre outros, que possa ser usado como fonte de informação, pode ser considerado como documento. ${ }^{21}$ Segundo Spink: ${ }^{22}$

\begin{abstract}
"Os documentos de domínio público são produtos sociais, tornados públicos. Eticamente estão abertos para análise por pertencerem ao espaço público, por terem sido tornados públicos de uma forma que permite a responsabilização. Podem refletir as transformações lentas em posições $e$ posturas institucionais assumidas pelos aparelhos simbólicos que permeiam o dia-a-dia ou, no âmbito das redes sociais, pelos agrupamentos e coletivos que dão forma ao informar,refletindo o ir e vir de versões assumidas ou advogadas". (p. 136)
\end{abstract}

Baseado nas informações disponibilizadas pela Internet, ${ }^{23-50}$ de agosto de 2006 a julho de 2007, foi feito um levantamento de 28 currículos de Cursos de Licenciatura em Química, de 21 Universi- 
dades Estaduais e Federais da Região Sudeste do Brasil. Destas, 11 disponibilizaram a grade curricular com os respectivos programas ou ementas, 5 disponibilizaram apenas a grade curricular e outras 5 não disponibilizaram nem mesmo a grade curricular. Desta forma, as informações analisadas neste trabalho são referentes a 16 Universidades, sendo 4 do estado de São Paulo, 7 de Minas Gerais, 3 do Rio de Janeiro e 2 do Espírito Santo, correspondentes a 22 cursos de Licenciatura em Química.

Inicialmente, foram obtidas informações sobre 1215 disciplinas, incluindo as de áreas de Química, Matemática, Física, Línguas e das denominadas áreas pedagógicas. No entanto, num segundo momento, optou-se por excluir da análise as disciplinas de áreas de formação geral, desvinculadas da área de Química, por não ser este o foco de interesse deste trabalho. Desta forma, foram selecionadas para análise 701 disciplinas (dentre obrigatórias e optativas) da área de Química e de ensino de Química. Realizou-se a análise de conteúdo (qualitativa e quantitativa) dos programas e/ou ementas destas disciplinas.

Para Bardin apud Reigota, ${ }^{1}$ a análise de conteúdo caracteriza-se pela "manipulação de mensagens" (conteúdos e expressões deste conteúdo) visando buscar indicadores que permitam inferir sobre uma outra realidade, diferente daquela da mensagem. Em análise qualitativa, a partir da presença do índice (tema, palavra, personagem, etc.) procuram-se descobrir os "núcleos de sentido" que compõem a comunicação, enquanto que na análise quantitativa o determinante é a frequiência com que o índice se apresenta no discurso.

Numa primeira etapa, as informações referentes às 701 disciplinas foram lidas e procurou-se encontrar, nos programas ou ementas das disciplinas, palavras que identificassem de alguma forma a abordagem de temas ambientais como, por exemplo, "meio ambiente, educador ambiental, implicações ambientais, questão ambiental, poluição, reciclagem, descarte de resíduos de laboratórios", entre outras. Após selecionar as disciplinas que aparentemente abordassem temas ambientais, realizou-se a análise de conteúdo dos respectivos programas. Pode-se dizer que a parte mais difícil da análise realizada foi buscar uma forma de classificar as disciplinas que abordavam temas ambientais, de acordo com a natureza destas abordagens. Inspirando-se em categorias propostas por Baía Júnior ${ }^{51}$ e Reigota, ${ }^{1}$ as disciplinas analisadas foram classificadas da seguinte forma: Categoria 1 - apresentação explícita nas ementas e programas, da abordagem articulada entre aspectos naturais e sociais; Categoria 2 - abordagem de aspectos científico-tecnológicos relacionados ao meio ambiente, mas que não considera as repercussões da atividade humana sobre o sistema natural e vice-versa; Categoria 3 - identificação de indício de abordagem ambiental por palavras contidas nos títulos das disciplinas devido à indisponibilidade de programas ou ementas.

\section{RESULTADOS E DISCUSSÃO}

Com relação à análise documental, palavras que de alguma forma indicassem a abordagem de temas ambientais como, por exemplo, meio ambiente, educador ambiental, implicações ambientais, questão ambiental, poluição, reciclagem, descarte de resíduos de laboratórios, entre outras, foram encontradas em 234 disciplinas (33\%) do total analisado (701).

Destas 234 disciplinas, somente 23 (10\%), foram classificadas de acordo com a Categoria 1, ou seja, conseguiu-se encontrar indícios da abordagem articulada entre aspectos naturais e sociais (Tabela 1). Vale destacar a aproximação entre a definição da Categoria $1 \mathrm{e}$ a nossa concepção de EA, que é concordante com a de Loureiro e colaboradores: ${ }^{52}$

"A Educação Ambiental é uma práxis educativa e social que tem por finalidade a construção de valores, conceitos, habilidades e atitudes que possibilitem o entendimento da realidade de vida e a atuação lúcida e responsável de atores sociais individuais e coletivos no ambiente. Nesse sentido, contribui para a tentativa de implementação de um padrão civilizacional e societário distinto do vigente, pautado numa nova ética da relação sociedade-natureza." (p. 69)

Algumas palavras e frases contidas nos programas analisados auxiliaram nesta classificação como, por exemplo, "Legislação ambiental: CONAMA e leis estaduais"; "As implicações ambientais, políticas e econômicas do desenvolvimento científico. As aplicações tecnológicas e suas conseqüências sociais"; "Problemas ecológicos contemporâneos (camada de ozônio, efeito estufa, chuvas ácidas, erosão, mineração e exploração de recursos naturais, queimadas e conteúdo de $\mathrm{CO}_{2}$ na atmosfera)"; "Reações químicas e processos de interesse para a saúde humana nas águas, no solo e na atmosfera. Legislação e poluição ambiental"; "Impacto ambiental... das atividades profissionais... responsabilidade como cidadão"; "Introduzir o estudante na reflexão sobre as relações entre química, meio ambiente e educação"; "Avaliar criticamente a aplicação do conhecimento químico tendo em vista o diagnóstico e o equacionamento de questões sociais e ambientais".

A Tabela 1 foi construída fazendo-se recortes nos programas ou ementas das disciplinas como, por exemplo, a disciplina "Química do Meio Ambiente", oferecida pelo Departamento de Química da Faculdade de Filosofia, Ciências e Letras de Ribeirão Preto-USP, apresentava em seu programa o objetivo de "Estimular o senso crítico do licenciando referente aos processos químicos que ocorrem no meio ambiente para que assim este possa atuar como um educador ambiental no ensino médio".

Segundo Reigota, ${ }^{53}$ a escola pode ser considerada como um dos locais privilegiados para construção da Educação Ambiental que, com a perspectiva de educação, deve permear todas as disciplinas, enquanto enfocar as relações entre a humanidade e o meio natural. É interessante notar que das 23 disciplinas classificadas na Categoria 1 , somente 15 são de caráter obrigatório.

As disciplinas não explicitadas como 'experimentais', cujas ementas ou programas continham conteúdos relacionados com a questão ambiental, mas restritos a aspectos técnicos, sem considerar as repercussões da atividade humana sobre o sistema natural e vice-versa, foram classificadas como Categoria 2 (Tabela 2). A seguir encontram-se alguns exemplos de assuntos abordados nas disciplinas Categoria 2: "Fontes de metais poluentes no ambiente"; "Aspectos toxicológicos e ambientais"; "Dar uma visão geral sobre os conceitos da poluição relacionados ao ambiente"; "O petróleo e seus derivados. Destilação do petróleo; Os tipos de queima: Poluição atmosférica provocada por compostos de carbono"; "Elementos, íons e substâncias químicas que possam, de algum modo, prejudicar o meio ambiente"

Em algumas das disciplinas contidas na Tabela 2 nota-se a preocupação com relação à segurança em laboratório químico, bem como estocagem e descarte de resíduos de laboratórios. Além das 11 disciplinas relacionadas na Tabela 2, todas as disciplinas de caráter experimental explícito nos programas ou ementas, ou mesmo no título (193), também foram classificadas como Categoria 2, tendo em vista a problemática da geração de resíduos químicos. Apenas pelo programa das disciplinas experimentais (com raras exceções) não foi possível avaliar se os resíduos gerados têm sido dispostos de forma adequada, ou mesmo se os alunos têm sido envolvidos com o tratamento e disposição desses resíduos. Porém, tendo em vista que várias das Universidades investigadas têm programas de tratamento de resíduo químico, partimos do pressuposto de que no mínimo seja feita a disposição dos resíduos em recipientes adequados durante a 
Tabela 1. Recortes dos programas ou ementas de disciplinas classificadas na Categoria 1

\begin{tabular}{ll}
\hline Disciplina/caráter & Recorte dos programas ou ementas
\end{tabular}

Química do Meio Ambiente/ obrigatória/ DQ/FFCLRP/USP

História e Filosofia da Ciência/ optativa/ DQ/FFCLRP/USP

Educação Ambiental/optativa/ DQ/FFCLRP/USP

Tratamento de Resíduos Químicos de Laboratórios de Ensino e Pesquisa/ optativa/ DQ/FFCLRP/USP

Ciências da Terra/optativa/ IQ-IF-ICMC/USP/São Carlos

Introdução ao Estudo da Química/ obrigatória/IQ/ UNESP/Araraquara ${ }^{\mathrm{e}}$

Introdução ao Estudo da Química/ obrigatória/IQ/ UNESP/Araraquara

Química, Meio Ambiente e Educação/ obrigatória/IQ (noturno)/USP/São Paulo

Química do Meio Ambiente/obrigatória IQ/UNICAMP

História da Química/ obrigatória/DQ/UFSCar

Introdução à Química Ambiental/ obrigatória DQ/UFSCar

Química Ambiental/

obrigatória/DQ/UFES

Química Ambiental/ obrigatória/

DQ(noturno)/UFMG

Fundamentos de Química Ambiental/ obrigatória/DQ (diurno)/UFMG

Química Ambiental/ obrigatória/ DQI/UFLA

Física do Solo e Conservação do Solo e da Água/optativa/DQI/UFLA

Objetivos: (...) senso crítico... referentes aos processos químicos que ocorrem no meio ambiente para que... possa atuar como um educador ambiental no ensino médio. Programa: (...) o papel do Químico na sociedade. Poluição da atmosfera urbana (...) Legislação ambiental: CONAMA e leis estaduais.

(...) implicações ambientais, políticas e econômicas do desenvolvimento científico. As aplicações tecnológicas e suas conseqüências sociais.

(...) a Questão Ambiental. (...) Ecologia e Ambientalismos. Plano Nacional de Educação Ambiental. Educação Ambiental e o Currículo Escolar (...)

Objetivos: (...) formação do químico contemporâneo (...) impacto ambiental de suas atividades profissionais (...) sua responsabilidade como cidadão. Programa: (...) preocupação com resíduos químicos (...)

Objetivos: (...) problemas ecológicos contemporâneos (camada de ozônio, efeito estufa, chuvas ácidas, erosão, mineração e exploração de recursos naturais, queimadas e conteúdo de $\mathrm{CO}_{2}$ na atmosfera etc.), (...)

Programa: (...) Conceituação - O que é Química? Interesses: Uma visão histórica. Os diversos campos da química. A química e sua relação com as outras ciências. O papel do químico na sociedade. A química e o ambiente. A química e o desenvolvimento econômico (...)

Programa: (...) O papel do químico na sociedade. A química e o ambiente. A química e o desenvolvimento econômico (...)

Objetivos: (...) relações entre química, meio ambiente e educação (...)

Programa: (...) Divulgação de conhecimentos e inserção da sociedade nas discussões dos problemas ambientais: o papel da escola e da comunidade.

Ementa: (...) Poluição ambiental: prevenção e tratamento. (...)

Objetivos: (...) Química (...) construção humana (...) suas relações com os contextos cultural, sócio-econômico e político. (...) aplicação do conhecimento químico (...) equacionamento de questões sociais e ambientais. (...)

Objetivos: (...) Preparar os futuros professores para o ensino de conceitos de Química Ambiental (...) Ementa: (...) Química Ambiental da atmosfera; (...) geosfera (...) Monitoração ambiental e Legislação Ambiental.

Ementa: (...) problemas de poluição. Substâncias tóxicas. A qualidade de vida (...)

Ementa: (...) Estudo de algumas relações ser vivo - meio ambiente. Legislação ambiental (...)

Ementa: Legislação ambiental (...) principais poluentes e resíduos no ecossistema. Tecnologia para controle ambiental. Processos de reciclagem de materiais. Prática: Análise de poluentes em resíduos (...)

Química ambiental: água, ar e solo. Comportamento de poluentes ambientais (...) transformação de poluentes e seus efeitos sobre a saúde, vegetação e materiais. (...)

Práticas e (...) Planejamento conservacionista (...)

Administração e Meio Ambiente/optativa/ DQI/ UFLA

Caracterização da problemática ambiental (...) gestão ambiental (...) política ambiental; responsabilidade social/ambiental das organizações; normatização ambiental e ISO 14000; tecnologia e meio ambiente (...)

Química Ambiental/ obrigatória/IQ/UFU

Ementa: (...) Atmosfera e a poluição do ar (...) poluição das águas (...) mar (...) solo (...) Proteção do meio ambiente.

Química Ambiental/optativa DQ/UFV

Ementa: Química dos poluentes (...) Poluição da água (...) solo (...) ar. Tratamento de resíduos. (...) avaliação de impacto ambiental. Legislação ambiental (...)

Introdução ao Controle Ambiental/ optativa/DQI/ UFLA

Introdução: (...) Poluição das águas (...) solo (...) legislação Ambiental e reciclagem de poluentes.

Objetivos: (...) principais problemas ambientais. (...) conhecimentos (...) para tratar questões ambientais.

Ementa: (...) problemas atuais de poluição atmosférica (...) Gerenciamento ambiental, minimização de resíduos e reciclagem (...) 
Tabela 1. continuação

\begin{tabular}{lc}
\hline Disciplina/caráter & Recorte dos programas ou ementas \\
\hline $\begin{array}{l}\text { Química Ambiental/ obrigatória/DQ (no- } \\
\text { turno)/ UFRRJ }\end{array}$ & (...) Ação Humana e Poluição Atmosférica (...) Controle da Poluição Atmosférica (...) Com- \\
bustíveis; Fontes Alternativas de Energia (...)
\end{tabular}
turno)/ UFRRJ

Programa: Queima ou combustão.Como são produzidos os gases poluentes. Produção da

Química Aplicada ao Ensino Médio II/ obrigatória/DQ (noturno)/UFRRJ chuva ácida. O controle da poluição: poluição x tecnologia. A acidez da chuva: $\mathrm{pH}$ da chuva,

pH da chuva ácida e pH do "solo". A formação da água. A água como solvente: soluções aquosas. Rapidez das transformações químicas. Leis da conservação da massa.Transformações e energia

DQ/FFCLRP/USP - Departamento de Química/Faculdade de Filosofia, Ciências e Letras de Ribeirão Preto/ Universidade de São Paulo; IQ-IF-ICMC/USP/São Carlos: Instituto de Química - Instituto de Física - Instituto de Ciências Matemáticas e de Computação/Universidade de São Paulo/São Carlos; IQ/USP/São Paulo: Instituto de Química/Universidade de São Paulo/São Paulo; IQ/UNICAMP: Instituto de Química/Universidade de Campinas; DQ/UFSCar: Departamento de Química/Universidade Federal de São Carlos; DQ/UFES: Departamento de Química/Universidade Federal do Espírito Santo; DQ/UFMG: Departamento de Química/ Universidade Federal de Minas Gerais; IQ/UFU: Instituto de Química/Universidade Federal de Uberlândia; DQ/UFV: Departamento de Química/Universidade Federal de Viçosa; DQI/UFLA: Departamento de Química/ Universidade Federal de Lavras; DCNAT/UFSJ: Departamento de Ciências Naturais/Universidade Federal de São João Del Rei; DQ (noturno)/UFRRJ: Departamento de Química/Universidade Federal Rural do Rio de Janeiro.

Tabela 2. Recortes dos programas ou ementas de disciplinas classificadas na Categoria 2

\begin{tabular}{lc}
\hline Disciplina/caráter/Universidade & Recorte dos programas ou ementas \\
\hline $\begin{array}{l}\text { Noções de Segurança em laboratório de } \\
\text { Química/ obrigatória/ DQ/FFCLRP/USP }\end{array}$ & $\begin{array}{r}\text { Programa: (...) contaminantes que afetam a saúde; (...) transporte e condicionamento de produ- } \\
\text { tos químicos (...) cuidados com o meio ambiente. }\end{array}$ \\
\hline $\begin{array}{l}\text { Química de Coordenação e Materiais/ } \\
\text { obrigatória/IQ (noturno)/USP/São Paulo }\end{array}$ & $\begin{array}{c}\text { Programa: (...) aspectos bioinorgânicos e ambientais: metais em sistemas biológicos, trans- } \\
\text { porte de oxigênio, processos enzimáticos, vitamina B12, fotossíntese, fixação do nitrogênio. } \\
\text { Aspectos toxicológicos e ambientais. }\end{array}$
\end{tabular}

Geoquímica de Ambientes Superficiais/ obrigatória/IQ (noturno)/USP/SP

Programa: (...) fontes de metais poluentes no ambiente.

\begin{tabular}{|c|c|}
\hline $\begin{array}{l}\text { Química com Segurança/ } \\
\text { obrigatória/ IQ/UNICAMP }\end{array}$ & Ementa: (...) Estocagem e Descarte de Resíduos de Laboratórios. Contaminação Química (...) \\
\hline $\begin{array}{l}\text { Segurança Química em L } \\
\text { optativa IQ/UNESP/Arar }\end{array}$ & $\begin{array}{l}\text { Ementa: (...) Substâncias químicas como agentes de risco à saúde humana (...) Gerenciamento } \\
\text { de resíduos químicos em laboratórios (...) }\end{array}$ \\
\hline $\begin{array}{l}\text { Segurança/ } \\
\text { a/DQI/UFLA }\end{array}$ & $\begin{array}{l}\text { (...) Estocagem e descarte de resíduos de laboratório (...) A contaminação química, Respons- } \\
\text { abilidade do químico com o ambiente de trabalho e com o meio ambiente. }\end{array}$ \\
\hline $\begin{array}{l}\text { Controle da Poluição Hídrica em } \\
\text { Áreas Rurais/ optativa/DQI/ UFLA }\end{array}$ & $\begin{array}{r}\text { (...) Tem por objetivo dar uma visão geral sobre os conceitos da poluição rela } \\
\text { ente (água, solo e ar), enfocando, em especial, a poluição hídrica }\end{array}$ \\
\hline $\begin{array}{l}\text { istória e Evolução da Química/ } \\
\text { brigatória/DQ (diurno e noturno)/UFRRJ }\end{array}$ & $\begin{array}{l}\text { (...) Panorama da química moderna: tópicos sugeridos: Química analítica (espectroscopias e } \\
\text { cromatografias), Química inorgânica (agregados - clusters), Química orgânica (sínteses estere- } \\
\text { oespecíficas), Bioquímica (engenharia genética, biologia molecular), Físico-química (cálculos } \\
\text { teóricos e modelagem com computador), Química ambiental e ecológica (...) }\end{array}$ \\
\hline $\begin{array}{l}\text { Ensino Médio I/ } \\
\text { rno)/UFRRJ }\end{array}$ & $\begin{array}{l}\text { Programa: O petróleo e seus derivados. Destilação do petróleo; Os tipos de queima: Poluição } \\
\qquad \text { atmosférica provocada por compostos de carbono (...) }\end{array}$ \\
\hline $\begin{array}{l}\text { Química dos elementos/ } \\
\text { obrigatória/DQ/UFSCar }\end{array}$ & $\begin{array}{c}\text { Objetivos: (...) elementos, íons e substâncias químicas que possam, de algum modo, prejudicar } \\
\text { o meio ambiente (...) Química descritiva do bloco s; Química descritiva do bloco p; Química } \\
\text { descritiva dos metais de transição; Noções de Química de Coordenação e da Química dos Com- } \\
\text { postos Organometálicos (...) }\end{array}$ \\
\hline $\begin{array}{l}\text { Experimentação para o Ensino de } \\
\text { Química I/ obrigatória/DQ/UFSCar }\end{array}$ & $\begin{array}{l}\text { (...) Evolução histórica da utilização de laboratórios no ensino de química; planejamento de } \\
\text { experimentos didáticos; o desenvolvimento de atividades experimentais nas aulas de química; } \\
\text { princípios gerais de segurança no laboratório e de descarte de resíduos (...) }\end{array}$ \\
\hline
\end{tabular}

DQ/FFCLRP/USP: Departamento de Química/Faculdade de Filosofia, Ciências e Letras de Ribeirão Preto/ Universidade de São Paulo; IQ/ USP/São Paulo: Instituto de Química/Universidade de São Paulo/São Paulo; IQ/ UNICAMP: Instituto de Química/Universidade de Campinas; IQ/UNESP/Araraquara: Instituto de Química/ Universidade Estadual Paulista/Araraquara; DQI/UFLA: Departamento de Química/Universidade Federal de Lavras; DQ/UFRRJ: Departamento de Química/Universidade Federal Rural do Rio de Janeiro; DQ/UFSCar: Departamento de Química/Universidade Federal de São Carlos. 
prática experimental, proporcionando a sensibilização dos alunos quanto à preservação ambiental. No Brasil, o final da década de 90 foi um importante marco na implementação de programas de gerenciamento de resíduos nas Universidades. ${ }^{54}$

Somente 7 disciplinas (Tabela 3) foram classificadas na Categoria 3, pois como não apresentavam informações, a análise foi feita baseando-se somente nos títulos. É importante notar a freqüência com que aparecem as disciplinas nomeadas como Química Ambiental (14 no total) que, segundo Mozeto e Jardim,,$^{55}$ surgiram na década de 80 no Brasil para suprir a carência de profissionais devidamente formados nesta área. Dentro da proposta de Mozeto e Jardim, ${ }^{55}$ as disciplinas de Química Ambiental poderiam se configurar em um primeiro passo para dar informações necessárias aos licenciandos em Química a fim de que estes atuem como educadores ambientais na Escola Básica.

Tabela 3. Títulos de disciplinas que revelam indícios da abordagem ambiental (Categoria 3)

\begin{tabular}{lc}
\hline Disciplinas/caráter & Universidade \\
\hline Química Ambiental/obrigatória & DQ/FC/UNESP/Bauru \\
Prática de Ensino em Educação & FUNEDI/UEMG \\
Ambiental/obrigatória & FUNEDI/UEMG \\
Química Ambiental/obrigatória & IQ/UERJ \\
Ciências Ambientais/obrigatória & IQ/UERJ \\
Tratamento de Resíduos & IQ/UERJ \\
Industriais/optativa & CEFETES \\
Educação Ambiental/optativa & Química Ambiental/obrigatória
\end{tabular}

DQ/FC/UNESP/Bauru: Departamento de Química/Faculdade de Ciências/Universidade Estadual Paulista/ Bauru; FUNEDI/UEMG: Fundação Educacional de Divinópolis/Universidade do Estado de Minas Gerais; IQ/ UERJ: Instituto de Química/Universidade do Estado do Rio de Janeiro; CEFETES: Centro Federal de Educação Tecnológica do Espírito Santo.

Ao analisar a relação entre a questão ambiental e propostas educacionais voltadas ao ambiente, Lima $^{7}$ considera que as propostas educacionais dominantes tendem a enfatizar os aspectos técnicos e biológicos da questão ambiental em detrimento de suas essenciais dimensões política e ética. Segundo este autor, essa tendência favorece concepções e práticas de educação ambiental conservadoras, despolitizadas e insustentáveis.

\section{CONSIDERAÇÕES FINAIS}

O baixo número de disciplinas classificadas como Categoria 1 (23 no total de 701) pode ser indicativo de que professores de Química da região Sudeste, durante sua formação inicial, têm poucas oportunidades de construírem uma sólida compreensão do elo existente entre os fenômenos químicos que ocorrem no meio ambiente e questões sociais, econômicas e culturais. Na maioria das vezes, nos programas e ementas analisadas as discussões que articulam as relações entre homem e natureza se restringem principalmente às disciplinas intituladas "Química Ambiental" ou equivalentes, que são de caráter optativo.

As análises realizadas indicam a ênfase dada ao tratamento e destinação adequada de resíduos químicos durante os cursos de Licenciatura em Química (197 em 701 disciplinas), uma vez que partimos do princípio de que em toda disciplina experimental faz-se pelo menos a coleta adequada dos resíduos químicos gerados durante a aula. Constatou-se que a maioria dos programas das disciplinas dos Cursos de Licenciatura em Química engloba aspectos científicotecnológicos relacionados ao meio ambiente. No entanto, não está explícita uma abordagem intensa sobre as repercussões da atividade humana sobre o sistema natural.

Em trabalho anterior, ${ }^{2}$ observou-se que a maioria das atividades de EA desenvolvidas na escola básica passa pela reciclagem do lixo e tem como objetivo principal a sensibilização e conscientização. Propostas e atividades de EA capazes de atingir a responsabilidade individual são menos freqüentes. A restrição ao tema do lixo pode ser um reflexo da ênfase dada ao tratamento e disposição de resíduos químicos durante a formação dos professores, neste caso, de Química. Também acreditamos que a ênfase dada nas disciplinas às discussões sobre aspectos científicos e tecnológicos possa contribuir para que os futuros professores de Química considerem que a intervenção predatória do homem possa ser modificada simplesmente pelo avanço do conhecimento científico.

Entendemos que a promoção de atividades visando a EA na escola básica não seja dependente exclusivamente da formação do professor, porém, para que a Química deixe de ser "desperdiçada" e possa efetivamente contribuir para abordar EA na escola básica, acreditamos que é urgente discutir a formação inicial de professores de Química.

Como mencionado anteriormente, estamos cientes que os dados apresentados neste trabalho não necessariamente refletem a abordagem ambiental no currículo de cursos de formação de professores, uma vez que o currículo analisado foi aquele apresentado aos professores, e não o currículo modificado e realizado por estes. No entanto, acreditamos que os dados apresentados tenham fornecido importantes indícios que poderão apoiar discussões futuras sobre a formação ambiental do professor de Química.

\section{REFERÊNCIAS}

1. Reigota, M. Em Pesquisa em Educação Ambiental; Kawasaki, C. S.; Motokane, M. T.; Matos, M. S., eds; Compacta Editora: Curitiba, 2007, cap. 2.

2. Abreu, D. G.; Campos, M. L. A. M.; Aguilar, M. B. R.; Quim. Nova 2008, 31, 688 .

3. Silva, T. T.; Documentos de Identidade - uma introdução às teorias do currículo, $2^{\mathrm{a}}$ ed., Autêntica: Belo Horizonte, 2007.

4. Carvalho, M. C. de M.; Educação Ambiental: a formação do sujeito ecológico, Cortez: São Paulo, 2004.

5. Santos, W. L. P.; Schnetzler, R. P.; Educação em Química: compromisso com a cidadania, $2^{\text {a }}$ ed., UNIJUÍ: Ijuí, 2000.

6. Guimarães, M.; A dimensão ambiental na educação, $2^{\mathrm{a}}$ ed., Papirus: São Paulo, 1998.

7. Lima, G. F. da C.; Ambiente \& Sociedade, NEPAM/UNICAMP: Campinas, 1999, 135.

8. Brasil. Ministério da Educação; Diretrizes e Bases da Educação Nacional. Lei ${ }^{\circ}$ 9.394, de 20 de dezembro de 1996, Diário Oficial da União, Brasília, no 248, 23/12/1996.

9. Brasil. Ministério da Educação. Secretaria de Educação Média e Tecnológica; Parâmetros curriculares nacionais: ensino médio, MEC/ SEMTEC: Brasília, 1999.

10. Tilbury, D.; Int. J. Environ. Educ. Inform. 1992, 11, 267.

11. Sorrentino, M.; Tese de Doutorado, Universidade de São Paulo, Brasil, 1995.

12. Brasil. Ministério da Educação; Diretrizes Curriculares Nacionais para os Cursos de Química, CNE/CES: Brasília, Parecer n 1303/2001.

13. de Andrade, J. B.; Cadore, S.; Vieira, P. C.; Zucco, C.; Pinto, A. C.; Quim. Nova 2004, 27, 358; de Andrade, J. B.; Pinto, A. C.; Cadores, S.; Vieira, P. C.; Zucco, C.; Pardini, V. L.; Curi, L. R. L.; Quim. Nova 2005, Suplemento, S7. 
14. Brasil; Programas Parâmetros em Ação, Meio ambiente na Escola: Caderno de Apresentação, Secretaria de Educação Fundamental/MEC: Brasília, 2001.

15. Moreira, A. F.; Silva, T. T. da.; Currículo, Cultura e Sociedade, $8^{\text {a }}$. ed., Cortez: São Paulo, 2005.

16. Sacristán, J. G.; O currículo: uma reflexão sobre a prática, $3^{\mathrm{a}} \mathrm{ed}$, Artmed: Porto Alegre, 2000.

17. http://www.viberoea.org.br/downloader.php?a=upload/ arquivos/0474382001149511705. pdf\&b=Hayde+Oliveira, acessada em Agosto 2007.

18. Bogdan, R.; Biklen, S.; Investigação qualitativa em educação, Porto Editora: Porto, 1994.

19. Sato, M.; Educação: teoria e Prática, Departamento de Educação do Instituto de Biociências da Universidade Estadual Paulista/Rio Claro, 2001, 9, 24.

20. Lüdke, M.; André, M. E. D. A.; Pesquisa em Educação: abordagens qualitativas, EPU: São Paulo, 1986.

21. Phillips, B. S.; Pesquisa Social, Agir: Rio de Janeiro, 1974.

22. Spink, P. Em Práticas discursivas e produção de sentido; Spink, M. J., org.; Cortez: São Paulo, 1999, cap. 5.

23. http: IIsistemas1.usp.br:8080/jupterweb/jupGradeCurricular?codcg=46 $\&$ codcur $=46012 \&$ codhab $=200 \&$ tipo $=N$, acessada em Agosto 2006 .

24. http://sistemas1.usp.br:8080/jupiterweb/jupGradeCurricular?codag=46 $\&$ codcur $=46200 \&$ codhab $=4 \&$ tipo $=\mathrm{N}$, acessada em Agosto 2006.

25. http:www.ffclrp.usp.br, acessada em Agosto 2006.

26. http://www.if.sc.br/grad/e_cursos_lic_grade.php, acessada em Setembro 2006.

27. http://www.fc.unesp.br/modules.php?name=Content $\&$ pa $=$ showpage $\& p$ id=133, acessada em Setembro 2006.

28. http://www.iq.unesp.br/graduacao-disciplinas-dolqn.php, acessada em Setembro 2006.

29. http://www.unicamp.br/prg/dac/catlogo2006/index.html, acessada em Setembro 2006.

30. http:www.prograd.ufscar.br/projetoped/projeto_licquimica.pdf, acessada em Fevereiro 2007.

31. http://www.divinopolis.uemg.br/quimica/index.asp?cquimica=curriculo, acessada em Fevereiro 2007.

32. http://www.qui.ufmg.br/graduacao/grade/licenciatura_diurno.php, acessada em Fevereiro 2007.

33. http://www.qui.ufmg.br/graduacao/grade/licenciatura_noturno.php, acessada em Fevereiro 2007.
34. http://www.ufu.br/condicoesofertas/, acessada em Março 2007.

35. http:www.ufv.br/pre/files/fra/catalogo2003/ementas/QUI.htm, acessada em Março 2007.

36. http://www.ufv.br/pre/files/fra/catalogo2006/13-CCE-Cursos.pdf, acessada em Março 2007.

37. http://www.ufsj.edu.br/Pagina/coqui/ementas.php, acessada em Março 2007.

38. http://www.efoa.br/, acessada em Abril 2007.

39. http://www.iq.uerj.br/arquivos/disciplinas_lic.pdf, acessada em Abril de 2007.

40. http://www.ice.ufrrj.br/dequim/grade_curricular.php?id_modalidade=5, acessada em Abril 2007.

41. http://www.ice.ufrrj.br/dequim/grade_curricular.php?id_modalidade=6, acessada em Abril 2007.

42. http://www.cce.ufes/dqui/licenciatura.htm, acessada em Maio 2007.

43. http://www.prg.ufla.br/informacoes_cursos/index_frame.htm, acessada em Maio 2007.

44. http://www.cefetes.br/content.aspx?chn=140, acessada em Maio 2007.

45. http://www.proac.uff.br/index.php?option-com_docman8task-cast_view, acessada em Junho 2007.

46. http://www.uenf.br/Uenf/Pages/CCT/Lcqui/?\&modelo=1\&cod_pag=8 $05 \&$ tabela $=\& \mathrm{np}=$ Licenciatura $+\mathrm{em}+$ Quimica $\&$ nc $=$ Ensino, acessada em Junho 2007.

47. http://www.siga.ufrj.br/sira/repositorio-curriculo/ListasCursos.html, acessada em Junho 2007.

48. http://www.ufabc.edu.br/index.php?p-cursos/descrição.php, acessada em Julho 2007.

49. http://www.ufjf.br/, acessada em Julho 2007.

50. http://www.fafeid.edu.br/, acessada em Julho 2007.

51. Baía Júnior, P. C.; Guimarães, D. A. A.; Resumos do II Encontro de Pesquisa em Educação Ambiental: abordagens epistemológicas $e$ metodológicas, São Carlos, Brasil, 2003.

52. Loureiro, C. F. B.; Layrargues, P. P.; Castro, S. de C.; Educação ambiental: repensando o espaço da cidadania, $2^{\mathrm{a}}$ ed., Cortez: São Paulo, 2002.

53. Reigota, M.; O que é Educação Ambiental, Brasiliense: São Paulo, 1994.

54. Abreu, D. G. de.; Tese de Doutorado, Universidade de São Paulo, Brasil, 2003; de Abreu D. G.; Costa C. R.; Assis, M. D., Iamamoto Y.; Quim. Nova 2006, 29, 1381.

55. Mozeto, A. A; Jardim, W. de F.; Quim. Nova 2002, Supl. 1, S7. 